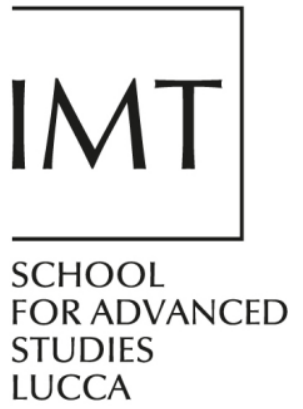

\#04

2015

SCHOOL

CED

LUCCA

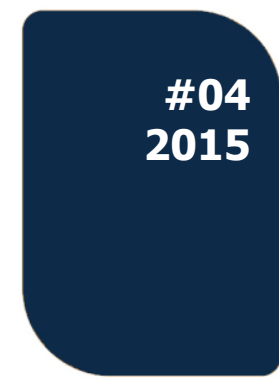

ISSN 2279-6894

IMT LUCCA EIC WORKING PAPER

SERIES 04

May 2015

Updated July 2017

RA Economics and institutional change

\title{
Organizing the Global Value Chain: a firm-level test
}

Davide Del Prete

Armando Rungi 


\section{Organizing the Global Value Chain: a firm-level test}

\section{Davide Del Prete}

IMT School for Advanced Studies Lucca

\section{Armando Rungi}

IMT School for Advanced Studies Lucca 


\title{
Organizing the Global Value Chain: a firm-level test
}

\author{
Davide Del Prete ${ }^{\dagger}$ \\ (IMT Lucca) \\ Armando Rungi ${ }^{\ddagger}$ \\ (IMT Lucca)
}

This version: May 2017

First version: August 2014

\begin{abstract}
In this paper we study the organization of Global Value Chains on a sample of about 4,000 manufacturing parent companies operating more than 90,000 affiliates on a global scale, which chose to integrate at least once in the period 2004-2012. Assuming a technological sequence of production stages, a recent property rights framework (Antràs and Chor, 2013; Alfaro et al., 2015) predicts that a choice of vertical integration is crucially based on both the position of a supplier along the chain and on the relative size of demand elasticities faced by the final producer and the supplier. We positively test whether, if final demand is sufficiently elastic (inelastic), producers of final goods integrate production stages that are more proximate to (far from) the consumers. However, this is not valid for cases of midstream parents, i.e. for producers of intermediate inputs that can integrate either backward or forward along the chain. We document that midstream are at least as common as are downstream parent companies but that existing theory neglects them. In these cases, we find that demand elasticities do not play a significant role in integration choices. Interestingly, both midstream and downstream parents tend to integrate affiliates that are more proximate in segments of a supply chain. Our findings point to a role for technological determinants that may be as important as are contracting frictions in organizing Global Value Chains.
\end{abstract}

Keywords: global value chains; vertical integration; outsourcing; property rights theory; multinational enterprises; downstreamness; corporate boundaries

JEL codes: F14, F23, D23, G34, L20.

\footnotetext{
† Mail to davide.delprete@imtlucca.it. Laboratory for the Analysis of Complex Economic Systems, piazza San Francesco 19 - 55100 Lucca - Italy.

‡ Mail to armando.rungi@imtlucca.it. Laboratory for the Analysis of Complex Economic Systems, piazza San Francesco 19 - 55100 Lucca - Italy.
} 


\section{Introduction}

Since the late 80s, technological progress and a decrease in trade barriers have fostered fragmentation of production on a global scale. ${ }^{1}$ Networks of firms have emerged across national borders along virtually international assembly lines. From the product design to the distribution to consumers, all intermediate stages of production may be ordered in technological sequences and dispersed in several countries. Each production stage along a supply chain can eventually be organized in two alternative ways: either keeping the stage within a corporate boundary, in case of vertical integration, or outsourcing it and engaging in arm's length contracts.

The aim of this paper is to test how firms shape the organization of Global Value Chains (GVCs). According to recent property rights frameworks ${ }^{2}$ (Antràs and Chor, 2013; Alfaro et al. 2015), an optimal allocation of ownership rights along the supply chain depends crucially on positions of suppliers along the sequence and on the relative size of elasticities of final demand when compared to the elasticity of substitution across production stages. Reasonably, the theory assumes that a downstream stage cannot commence if an upstream stage does not deliver an input, therefore contractual frictions may be present along supply chains. In fact, all intermediate producers and the final producer have to rely on a partition of the surplus extracted from the sale of the final product. Outsourcing provides suppliers with better incentives to invest in quality, but integration provides the firm with a better bargaining position by virtue of its residual rights of control. In this framework, a relation-specific investment made by any upstream supplier can affect incentives to invest by downstream suppliers. Eventually, the main prediction is that a firm integrates the production stages that are more proximate to (far from) the final consumer, if the demand for its product is sufficiently elastic (inelastic).

We find that the theory is valid for producers of final goods (i.e., downstream parents), starting integration backward from the bottom of a supply chain. However, we document that midstream parents are at least as common as are downstream parents. Indeed, we may think of many real-world cases of companies whose main output is an intermediate and not a final product, and can integrate other intermediate producers, both backward and forward. In this case, we find that the role of demand elasticities as a driver of integration is less relevant.

More interestingly, we find that both downstream and midstream parents systematically prefer to integrate production stages that are proximate along segments of the supply chain. The latter finding is robust across different specifications and several robustness checks. We point to a role for technological determinants that may be as important as are contracting frictions in shaping the organization of GVCs, for which extensions of the theory may be needed. We presume that economies of scope exist when companies coordinate production stages that share technological characteristics, while sourcing dissimilar stages from arm’s length suppliers.

To grasp the essential aspects of our findings, let us consider two case studies of downstream parents and two cases of midstream parents sourced from our data, in the upper and bottom panels, respectively, of Figure 1. For each case, we plot the relative positions on the supply chain of both the parent company and its affiliates, together with the demand elasticity faced by the parent. ${ }^{3}$

\footnotetext{
${ }^{1}$ See Baldwin and Lopez-Gonzalez (2014) and, previously, Hummels et al. (2001) for a discussion on the relevance of the phenomenon and on the structural economic changes it entails.

${ }^{2}$ For a review of the successful story of the property rights framework applied to the theory of the firm, see Aghion and Holden (2011). They retrace how Coase (1937) initiated, Williamson (1971, 1975, 1979) followed, and, finally, Grossman and Hart (1986) carved the theory of the firm in economic literature, when using theoretical models of incomplete contracts to understand what determines a firm's boundaries.

${ }^{3}$ Downstreamness metrics are sourced from Antràs and Chor (2013) and demand elasticities from Broda and Weinstein (2006). The boundaries of the firms are taken as at the end of 2012. See Section 3 and the Data Appendix for more details.
} 
Let us start from downstream parents. Sony and Johnson \& Johnson control 405 and 353 affiliates, respectively. The former is a group that originated in Japan and is primarily focused on electronics manufacturing. The latter is a US multinational corporation producing medical devices and pharmaceutical products. From our data, both exhibit similar positions (a downstreamness of 0.87 and 0.92 , respectively) on the supply chain, but they face different demand elasticities. Following the theoretical predictions by Antràs and Chor (2013) and Alfaro et al. (2015), Sony integrates more upstream, having a relatively lower demand elasticity, whereas Johnson \& Johnson integrates more downstream, having a relatively higher demand elasticity.

Figure 1: Cases of downstream and midstream parents: determinants of integration

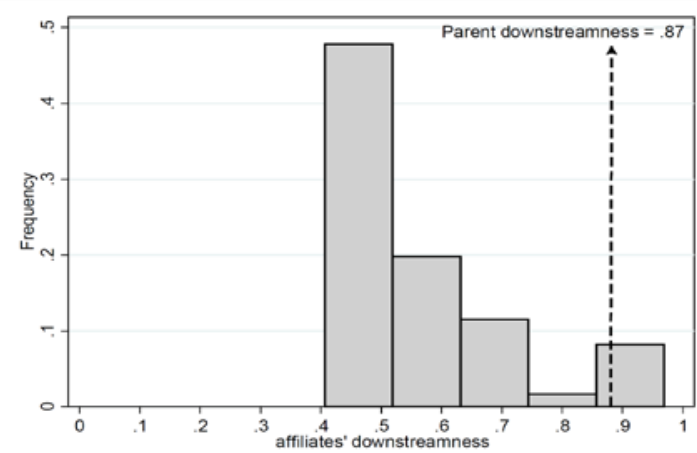

a) Sony, output demand elasticity (4.79) is below median.

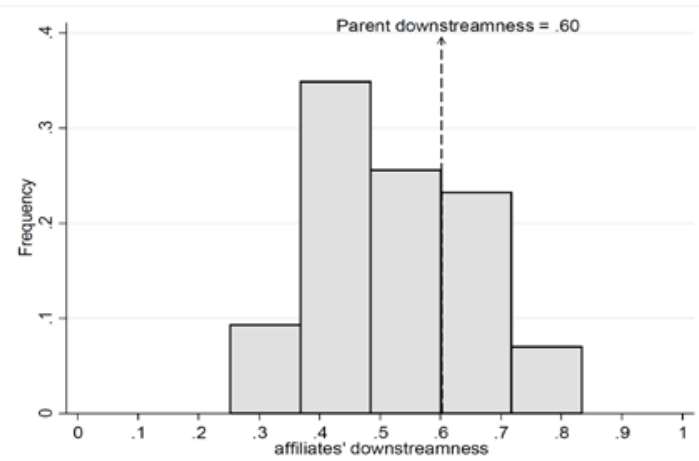

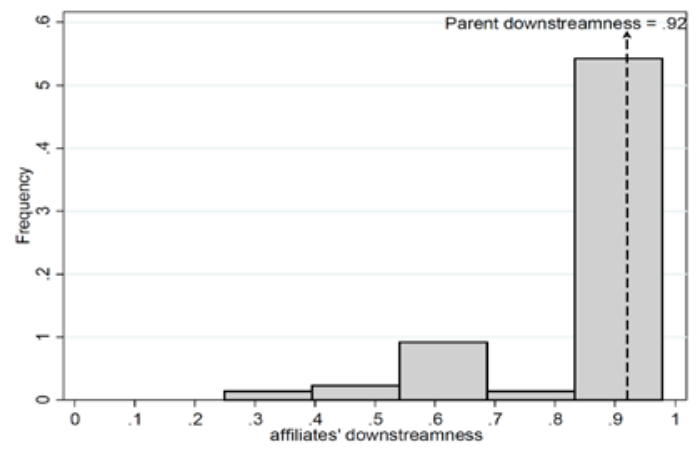

b) Johnson \& Johnson, output demand elasticity $(12.72)$ is above median.

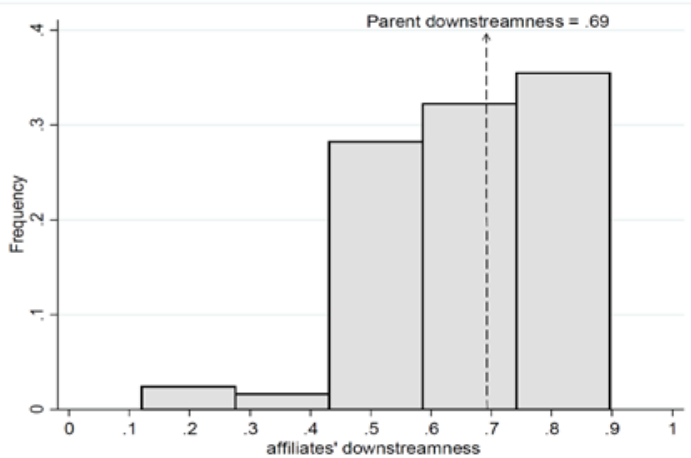

c) Hill and Smith, output demand elasticity (4.66) is d) Continental AG, output demand elasticity (6.79) below median. is above median.

At the bottom of Figure 1, Hill \& Smith Holdings PLC and Continental AG are midstream parents that integrate stages in both directions of the technological sequence. The first is a UK-based group active in manufacturing and supplying infrastructure products. The second is a world leading German producer of tyres, brakes, and other components for the automotive industry. They control 127 and 279 affiliates, respectively. Hill \& Smith integrates relatively more upstream, whereas Continental seems to integrate relatively more downstream, but the different propensities toward vertical integration are not as remarkable, as is the closeness between parent and average affiliate position. Thus, they seem to be involved in stages that are proximate on the technological sequence.

More particularly, take the case of Continental AG. It started in 1871 as a general rubber manufacturer. 
Over time, it extended its boundary both backward and forward along the automotive chain. Among others, Continental AG integrated the production of brakes and chassis in 1998, and it concluded a deal with Morotola in 2006 for the control of its automotive electronics unit. Then, the company acquired the VDO brand by Siemens for powertrain and fuel injection systems in 2007. More recently, in 2015, the company extended its scope further upstream with the acquisition of the US firm Vejance Technologies, which is a supplier of engineered rubber products.

Eventually, such proximity on the technological sequence is systematic in following analyses in both cases of midstream and downstream parent companies.

The remainder of this paper is organized as follows. In Section 2 we briefly review related works. Section 3 introduces the construction of our sample and first evidence from descriptive statistics. In Section 4 we present empirical analyses and several robustness checks. Section 5 concludes.

\section{Literature review}

Several past works have investigated the determinants of cross-border vertical integration, i.e., the global decision whether to 'make or buy', in the context of contractual frictions. ${ }^{4}$ It is only recently that scholars have started to consider the sequential nature of contracting and technology as an implicit feature of GVCs.

Acemoglu et al. (2007) were the first to analyze the consequences when unique headquarters have to commit to contracts with multiple suppliers, in this way extending the scope of the one-shot 'make or buy' decision of previous works. They showed that a greater contractual incompleteness leads to the adoption of less advanced technologies, even more so when intermediate inputs are highly complementary. Further efforts were made by Harms et al. (2012), who considered the role of transportation costs and their non-monotonic effects on an underlying chain of production, and by Costinot et al. (2013), who derived a sequential multi-country model in which mistakes can occur with a given probability along the chain. Hence, countries with relatively higher probabilities of making mistakes, i.e., performing more knowledge-intensive tasks, are better situated upstream in a production chain, where destruction of value has minimal impact.

Antràs and Chor (2013) focused more specifically on the integration choices of GVCs, when suppliers perform production stages that are sequential in nature, and contracts are all potentially incomplete. For the first time, they introduced a model with technological order in production stages, modelling a dependence of downstream stages from upstream stages. If an upstream stage does not deliver the intermediate input, a downstream strage cannot produce. Eventually, a relation-specific investment made by each supplier in the sequence potentially increases the value of the final product at the end of the chain. In this framework, a firm and its suppliers bargain sequentially on the basis of an expected surplus that is realized only after the sale of the final good. On the same line, Alfaro et al. (2015) proposed a generalization of the previous model, with contractual asymmetries along the supply chain, which comes to a similar conclusion. In this context, the relative size of the elasticity of output with respect to the elasticity of substitution across production stages crucially determines the direction of integration on the supply chain.

In fact, we find evidence for the main prediction by Antràs and Chor (2013) and Alfaro et al. (2015), according to which a company producing a final good (i.e. a downstream parent) tends to integrate stages that are more upstream (downstream), when the elasticity demand for the output is relatively lower (higher). We also find a role for contractual asymmetries, in line with the generalization of the model by Alfaro et al. (2015), according

${ }^{4}$ For a detailed review of firms' organization strategies and trade, we refer to Antràs and Yeaple (2014). 
to which the direction of vertical integration, i.e., whether relatively more upstream or dowsntream, tends to be where contracts are overall easier to enforce.

However, we find that demand elasticities are not a significant determinant of integration in the case of midstream parents. In fact, we show that cases of producers of intermediate outputs that integrate both backward and forward are very common. They violate the main stringent assumption of existing theoretical models, according to which integration always starts from the bottom of the supply chain. These findings emerge only after we explicitly control for the position of both the parent and its affiliates along the chain. In this we differ from Alfaro et al. (2015), who instead find general validation of their prediction on the role of the demand elasticity, but aggregating information about the production activities at the parent-level.

Our findings are robust to different sample compositions, firm-level heterogeneity, and different institutional environments of both origin and host countries. In this way, we also take into account country-specific determinants of internalization, as suggested by existing models (see, among others, Nunn, 2007; Corcos et al., 2012)

Interestingly, we find that both downstream and midstream parent companies prefer to integrate affiliates that are close enough along segments of the supply chain. To the best of our knowledge, the latter finding is neither predicted nor tested by existing contributions on GVCs. We presume that a role is played by economies of scope in technology, since a segment of a supply chain may be easier to manage from headquarters when its industries share some technological characteristics.

\section{Sample construction and preliminary evidence}

\subsection{Sample construction}

For the scope of our analysis, we focus on manufacturing parents that integrated an affiliate at least once in 20042012. ${ }^{5}$ Following international standards ${ }^{6}$, we assume an affiliate is controlled by a parent company when the latter has either a direct or an indirect stake of at least $50.01 \%$ in equity. Data are sourced from the Orbis and Zephyr databases, both compiled by Bureau Van Dijk. ${ }^{7}$

From Zephyr, we consider a company to be the target of a brownfield direct investment operation by a parent company if the latter reaches either a direct or an indirect equity stake higher than $50 \%$ after an M\&A deal is completed. Conversely, we consider an affiliate as a greenfield direct investment operation made by a parent company if: i) the first has been established in 2004-2012; ii) the affiliate has never been acquired by another parent company after an M\&A deal since incorporation. Therefore, we consider both brownfield and greenfield investment operations as new integration choices made by a unique controlling parent. The parent company may already have a set of affiliates at the moment of new integration choices, which we include in our analyses. See Appendix A for further details on the sample and its stratification.

\footnotetext{
${ }^{5}$ Our choice is motivated by the fact that metrics for testing determinants of integration are available only for recent decades, possibly catching technological advances and modern consumer preferences. Indeed, using them as determinants of past integration choices may introduce an endogeneity/simultaneity bias in our estimates. Please note that modern corporate boundaries are often the product of centuryold stories of vertical integration. From our data, the average age of companies that never integrated in $2004-2012$ is about 71 years. In Table 5 we include a control group for these cases.

6 The procedure for the identification of corporate boundaries is the same acknowledged in UNCTAD (2016) as a standard, following the algorithm proposed by Rungi et al. (2016). It is also in line with manuals for national statistics of MNEs proposed by OECD (2005) and UNCTAD (2009). In Appendix A and related figures, we report a descriptive example of our stratified data structure.

7 Bureau Van Dijk is a consultancy firm that collects standardized firm-level information on a world basis. It produces both the Zephyr database, which collects information on about 1.5 million M\&A deals, and the Orbis database, which collects financial accounts for about 200 million firms.
} 
We exclude from our baseline analysis parent companies whose output is not a manufactured product (i.e., financial companies, consultancy firms, utilities), which may not be strictly considered as organizing supply chains. By definition, stand-alone firms, who never integrated any affiliate, are also excluded from our study.

We end up with a sample of 4,192 manufacturing parents, which acquired or established 28,638 new affiliates in 2004-2012. Overall, they control a total of 90,298 affiliates in 151 countries. On average, a representative parent controls 2.63 affiliates. Approximately $63 \%$ of our sample is made of multinational groups, for which a parent reports at least one foreign affiliate.

From our data construction, we derive three control groups that are excluded from baseline estimations but are exploited later for robustness checks: a) a sample of 72,868 direct investment operations made by nonmanufacturing parents in 2004-2012, which includes parent companies not explicitly engaged in GVCs (financial companies, utilities, consultancy firms, etc); b) a sample of 20,991 portfolio investment operations, i.e., affiliates in which our parent companies acquired only minority stakes; c) a sample of 110,104 direct investment operations made by manufacturing parents in the period before 2004, when metrics of position, demand elasticities, and financial accounts are not available to us.

In Table 1 we provide a geographic coverage of our baseline sample by representative countries/areas. Details of our three control groups are included in Appendix A.

Table 1: Sample geographic coverage: origin by country of parent companies

\begin{tabular}{|c|c|c|c|c|}
\hline Economy & Parents & $\begin{array}{l}\text { All affiliates } \\
\qquad(\mathrm{A}+\mathrm{B})\end{array}$ & $\begin{array}{l}\text { Affiliates as before } \\
2004-2012 \\
\text { (A) }\end{array}$ & $\begin{array}{l}\text { Newly integrated } \\
\text { affiliates } \\
\text { (B) }\end{array}$ \\
\hline OECD & 3,356 & 84,047 & 58,492 & 25,555 \\
\hline non-OECD & 836 & 6,251 & 3,168 & 3,083 \\
\hline European Union & 1,405 & 40,375 & 27,986 & 12,389 \\
\hline United States & 1,404 & 29,462 & 19,452 & 10,010 \\
\hline $\begin{array}{l}\text { Rest of the world } \\
\text { of which: }\end{array}$ & 1,383 & 20,461 & 14,222 & 6,239 \\
\hline Japan & 285 & 11,351 & 9,215 & 2,136 \\
\hline Latin America & 50 & 543 & 178 & 365 \\
\hline Middle East & 47 & 628 & 406 & 222 \\
\hline China & 153 & 615 & 264 & 351 \\
\hline Africa & 24 & 547 & 415 & 132 \\
\hline ASEAN & 211 & 962 & 585 & 377 \\
\hline Total & 4,192 & 90,298 & 61,660 & 28,638 \\
\hline
\end{tabular}

Manufacturing parents are classified by their country of origin in the second column. First, we report their integration choices in 2004-2012, then we describe the number of affiliates they already controlled as a stock before 2004. In line with previous works studying FDI operations, we register in our sample a majority of investors in capital-abundant countries, as the bulk of parent companies originate in OECD countries. Among these, the EU 
and the US report the largest shares of parents (around 34\% in both cases) and controlled affiliates (45\% and 33\%, respectively). Among non-OECD economies, China and members of the Association of South-East Asian Nations (ASEAN) are the most represented in our sample.

For the scope of our analysis, we match firm-level primary activities at the 6-digit of the NAICS classification with similarly disaggregated industrial metrics of demand elasticity, ${ }^{8}$ sourced from Broda and Weinstein (2006), and positions on supply chains, sourced from Antràs and Chor (2013). In the absence of original information on actual shipments of intermediate inputs, Antràs and Chor (2013) ${ }^{9}$ turn to Input-Output tables to locate an industry along a supply chain, which is measured as the technological distance from final consumers. Metrics are normalized on a range $(0,1)$, where 0 is the ideal start of a production line and 1 represents final consumption.

In Section 4.3, we will also make use of the more recent bilateral measure for position on the chain proposed by Alfaro et al. (2015), ${ }^{10}$ which abandons the assumption of a unique technological sequence. The Relative Upstreamness is very useful to proxy the distance between each input and each output along a chain; however, it abandons the orientation to final demand. It indicates the relative distance of the input from a specific output, where the latter can also be an intermediate industry. For the sake of comparison across metrics, we invert it and obtain a similar range $(0,1)$ in Relative Downstreamness. Inputs approaching the value 1 are more proximate to the (final or intermediate) output. However, we will adopt the previous Absolute Downstreamness in baseline estimates, while keeping the novel bilateral measure as a robustness check. See Section 4.3 for comments on the complementary information provided by the estimates of both the Absolute Downstreamness (Antràs and Chor, 2013) and the Relative Downstreamness (Alfaro et al., 2015) in testing the theory.

We complement our dataset with measures that have been identified as systematic determinants for transactions within firm boundaries. First, we add parent-level variables. Labor productivity allows controlling for the fact that the most productive firms have the highest probability to integrate abroad, as suggested by Antràs and Helpman (2004) and Helpman et al. (2004). Capital intensity is usually positively associated with a larger share of intra-firm trade (Antràs, 2003). Firm size, age, number of already established affiliates, and multinational status allow us to control whether larger and older parents can more easily afford the sunk costs of a vertical integration decision (Blomström and Lipsey, 1991), especially when they are already multinational (Greenaway and Kneller, 2007).

Finally, we include a measure of Contractibility matched with activity of affiliates. It is sourced from Antràs and Chor (2013) and is based on the methodology of Nunn (2007). It ranks industries by easiness in reaching a deal with a supplier, in the spirit of both Rauch (1999) and Nunn and Trefler (2008). Two other country level variables control for the institutional environment of the hosting country: i) Rule of Law assesses the extent to which agents both have confidence in and abide by country rules (Nunn, 2007); ii) Entry Cost measures the cost of starting a business in a country as a percentage of income per capita, both sourced from the World Bank (2015).

\footnotetext{
${ }^{8}$ We source from US BEA correspondence tables from NAICS to 2002 I-O industry codes (IO2002). Some companies can report more than one primary activity, based on their conglomerate nature. This is the case for $17 \%$ of parents and $33 \%$ of affiliates. In these cases, we use average values by firm. We control later in the analyses for the robustness of findings when excluding such cases.

9 Metrics of position based on I-O tables were first proposed by Antràs et al. (2012) and inspired by Fan and Lang (2000); no technological sequence was assumed in these metrics. The extension of the US I-O tables to other countries is justified by the assumptions of a common technology frontier, a Leontief production function, or cross-country factor price equalization. Indeed, as in Acemoglu et al. (2009) and Alfaro et al. (2016), we can reasonably expect a strong correlation in input usage across countries. Antràs and Chor (2013) produce two alternative metrics of (absolute) downstreamness (see Appendix B for details). Here, we introduce results of the first (DuseTuse), because we do not find structural differences in estimates with the second (DownMeasure). Results with the DownMeasure are available upon request.

10 We thank Alfaro et al. (2015) for the provision of the Relative Upstreamness and related codes for computation. We converted from SIC rev. 1987 to NAICS rev 2007 using correspondence tables from US Census Bureau. We merged their industry-by-industry measure with our firm-level data structure. See Section 3 and Appendix B for further details. Possible mistakes are our exclusive responsibility.
} 


\subsection{Parents and affiliates on supply chains}

Against this background, we can detect the position of each parent and each affiliate in Figure 2, based on their industry affiliations. In Table 2 we report descriptive statistics for positions and demand elasticities. We assume that the primary activity of the (manufacturing) parent company also indicates the main activity of the corporate boundary, whereas the primary economic activities of affiliates represent production stages that have been integrated. ${ }^{11}$ Later in our analyses, we perform robustness checks of the validity of these assumptions.

Figure 2: Position of parent companies and affiliates along the supply chain

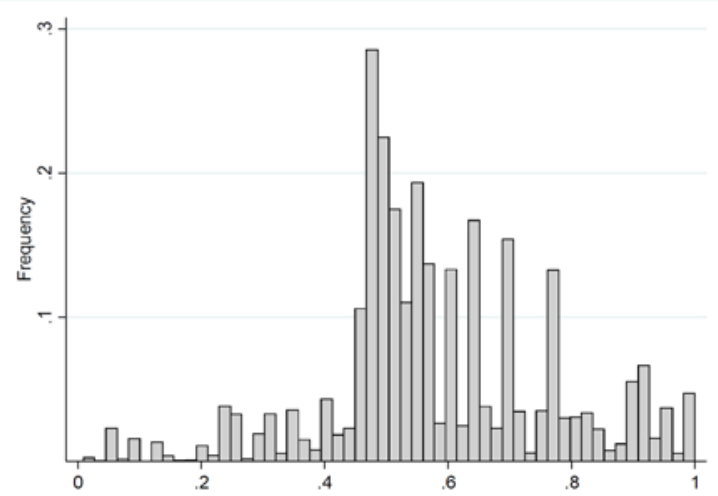

a) Parent-level downstreamness

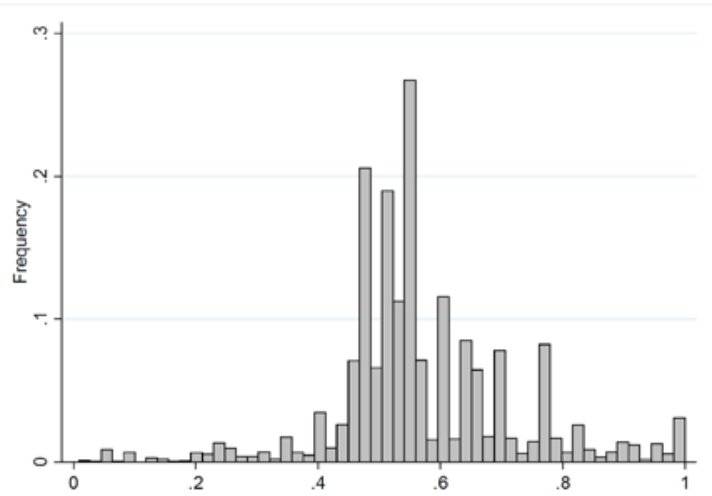

b) Affiliate-level downstreamness

Table 2: Absolute Downstreamness and elasticities of substitution across firms

\begin{tabular}{|c|c|c|c|c|c|c|c|}
\hline & Metrics & Obs. & Mean & Median & St. dev. & Min & Max \\
\hline \multirow[t]{2}{*}{ Parents } & Downstreamness & 4,192 & .63 & .65 & .22 & .07 & 1 \\
\hline & Elasticity of substitution & 4,192 & 8.85 & 5.97 & 9.99 & 1.3 & 108.5 \\
\hline \multirow[t]{2}{*}{ Affiliates } & Downstreamness & 90,298 & .58 & .54 & .16 & .01 & 1 \\
\hline & Elasticity of substitution & 90,298 & 7.39 & 3.76 & 8.39 & 1.3 & 108.5 \\
\hline \multirow{2}{*}{$\begin{array}{l}\text { Parent vs. } \\
\text { affiliates } \\
\text { (within) }\end{array}$} & Difference in Downstreamness & 90,298 & .05 & .01 & .24 & -.91 & .94 \\
\hline & Difference in Elasticity of substitution & 90,298 & 1.51 & .00 & 11.60 & -95.78 & 105.46 \\
\hline
\end{tabular}

From the combined reading of Figure 2 and Table 2, we document some important descriptive findings. More often than not, the output of a representative parent company is an intermediate good. The average Absolute Downstreamness for parents is 0.63 . The representative company starting integration is indeed located midstream on the technological sequence.

\footnotetext{
11 More than one affiliate controlled by a parent can perform the same production stage within its corporate boundary. We find about $23 \%$ of cases in our sample, when the activity by an affiliate is a duplicate at the industry-country level. Different qualities of inputs and/or geographic proximity to factories may determine multiple integrations of the same stage.
} 
In the case of affiliates, the average Absolute Downstreamness is 0.58. If we calculate the average difference in downstreamness ${ }^{12}$ of each parent from its affiliates (i.e., the difference within a corporate boundary), we obtain a value of 0.05 . That is, a representative parent is slightly more downstream than are its affiliates. At the same time, a parent is, on average, proximate to its integrated affiliates along the supply chain. The median values and the standard deviations support these findings.

This evidence is, prima facie, in contradiction with assumptions from existing theory, according to which a parent company is usually a producer of final goods integrating backward, as in Antràs and Chor (2013) and Alfaro et al. (2015). Also, proximity on the supply chain has been rather neglected in previous GVCs' studies. Eventually, our evidence implies a fragmentation of supply chains by segments, either integrated or not integrated within different corporate boundaries. Table 2 further includes descriptives of demand elasticities faced by parents and affiliates, which do not show significant differences in distributions.

\section{Empirical strategies}

\subsection{Baseline and robustness checks}

Our aim is to explain the position of an integrated affiliate along a value chain as a function of the position of the parent and its demand elasticity. We estimate the following baseline equation, augmented with firm, industry, and country level information:

$$
Y_{i(j) c}=\beta_{0}+\beta_{1} X_{j}+\beta_{2} \rho_{j}^{*}+\beta_{3}\left(\rho_{j}^{*} \cdot X_{j}\right)+\beta_{4} Z_{j}+\beta_{5} W_{i}+\beta_{6} V_{c}+\varepsilon_{i(j) c},
$$

where $Y_{i(j) c}$ is the $i$ th affiliate downstreamness integrated by the jth parent and operating in country $c$.

Among independent variables, $X_{j}$ stands for $j$ th parent downstreamness, and $\rho_{j}^{*}$ is a latent variable for parent demand elasticity, equal to one when above the median and zero otherwise, which is calculated following theory (Antràs and Chor, 2013). We split the sample by industry and use the median elasticity value (5.97) to reproduce cases of sequential substitutes (when elasticity is below the median) and sequential complements (when elasticity is above the median). Further, we interact $\rho_{j}^{*}$ with the position of the $j$ th parent along the supply chain. The inclusion of an interaction term is pivotal to derive marginal effects of demand elasticity (taking into account coefficients $\beta_{2}$ and $\beta_{3}$ with average parent downstreamness) and of parent downstreamness (taking into account $\beta_{1}$ for sequential substitutes and $\beta_{1}+\beta_{2}$ for sequential complements). Additionally, $Z_{j}$ collects parent-level controls in logarithmic scale: these are labor productivity, capital intensity, firm size, age, number of already established affiliates, and multinational status. In Wi we collect the affiliate's industry contractibility, and in $V_{c}$ we include host country controls for institutional environments, possibly substituted by country fixed effects in nested specifications, allowing us to control for country and industry-specific determinants of internalization, as suggested by Nunn (2007) and Corcos et al., (2012). Results are reported in Table 3.

We find that parents producing final goods integrate suppliers that enter further downstream, when output

\footnotetext{
12 From now on, downstreamness indicates Absolute Downstreamness, if nothing else is specified. Relative Upstreamness is used from Section 4.2 onward.
} 
demand is sufficiently elastic. This result is in line with basic predictions by Antràs and Chor (2013) and, more recently, by Alfaro et al. (2015). If we take the estimates of column 3 of Table 3 as reference, the marginal effect of parent elasticities on affiliate downstreamness is positive for values of parent downstreamness that are higher than 0.57 . That is, the prediction is valid for the segment of downstreamness where we will likely find producers of final goods.

Table 3: Baseline estimates

\begin{tabular}{|c|c|c|c|c|c|}
\hline Dependent variable: & (1) & (2) & (3) & (4) & (5) \\
\hline affiliate downstreamness $i(j) c$ & OLS & $\begin{array}{l}\text { OLS \& firm } \\
\text { controls }\end{array}$ & $\begin{array}{l}\text { OLS, firm } \\
\text { controls \& fe }\end{array}$ & $\begin{array}{l}\text { OLS, firm } \\
\text { controls \& fe }\end{array}$ & $\begin{array}{l}\text { OLS, firm } \\
\text { controls \& fe }\end{array}$ \\
\hline \multirow[t]{2}{*}{ parent downstreamness $_{j}$} & $.150 * * *$ & $.224 * * *$ & $.231 * * *$ & $.372 * * *$ & $.188 * * *$ \\
\hline & $(.019)$ & $(.036)$ & $(.033)$ & $(.031)$ & $(-.051)$ \\
\hline \multirow[t]{2}{*}{ complements $_{j}$} & $-.040 * * *$ & $-.055 * *$ & $-.062 * *$ & .023 & $-.069 *$ \\
\hline & $(.015)$ & $(.028)$ & $(.026)$ & $(.027)$ & $(.038)$ \\
\hline \multirow[t]{2}{*}{ complements* parent downstreamness $_{j}$} & $.060 * *$ & $.102 * *$ & $.108^{* * *}$ & -.043 & $.138 * *$ \\
\hline & $(.026)$ & $(.044)$ & $(.041)$ & $(.047)$ & $(.059)$ \\
\hline \multirow[t]{2}{*}{ (log of) labor productivity $j$} & & $.009 *$ & $.007 *$ & .007 & $.010 * *$ \\
\hline & & $(.005)$ & $(.004)$ & $(.008)$ & $(.005)$ \\
\hline \multirow[t]{2}{*}{ (log of) capital intensity $j$} & & $-.011 * *$ & -.008 & $-.015^{* *}$ & $.014 *$ \\
\hline & & $(.005)$ & $(.005)$ & $(.007)$ & $(.007)$ \\
\hline \multirow[t]{2}{*}{ (log of) employment ${ }_{j}$} & & $.006 *$ & $.006 * *$ & $.009 * *$ & $.009 * *$ \\
\hline & & $(.003)$ & $(.003)$ & $(.004)$ & $(.004)$ \\
\hline \multirow[t]{2}{*}{ (log of) number of affiliates $j$} & & $-.007 *$ & -.006 & -.005 & $-.018 * * *$ \\
\hline & & $(.004)$ & $(.003)$ & $(.004)$ & $(.005)$ \\
\hline \multirow[t]{2}{*}{ (log of) age $e_{j}$} & & -.005 & -.004 & .005 & $-.012 * * *$ \\
\hline & & $(.005)$ & $(.004)$ & $(.006)$ & $(.005)$ \\
\hline \multirow[t]{2}{*}{ multinational group $\boldsymbol{j}$} & & $-.034 * * *$ & $-.042 * * *$ & $-.061 * * *$ & .002 \\
\hline & & $(.011)$ & $(.010)$ & $(.013)$ & $(.015)$ \\
\hline \multirow[t]{2}{*}{ contractibility $i_{i}$} & & $-.190 *$ & $-.205 * * *$ & $-.309 * * *$ & -.038 \\
\hline & & $(.099)$ & $(.028)$ & $(.031)$ & $(.041)$ \\
\hline \multirow[t]{2}{*}{ rule of law c } & & -.012 & & & \\
\hline & & $(.013)$ & & & \\
\hline \multirow[t]{2}{*}{ contractibility*rule of law ic } & & -.001 & & & \\
\hline & & $(.122)$ & & & \\
\hline \multirow[t]{2}{*}{ entry cost $c$} & & $-.004 * * *$ & & & \\
\hline & & $(.001)$ & & & \\
\hline \multirow[t]{2}{*}{ Constant } & $.487 * * *$ & $.518^{* * *}$ & $.206 * * *$ & $.357 * * *$ & $.530 * * *$ \\
\hline & $(.012)$ & $(.044)$ & $(.053)$ & $(.049)$ & $(.047)$ \\
\hline Observations & 90,274 & 30,340 & 39,808 & 19,482 & 15,111 \\
\hline Adjusted R-squared & .082 & .158 & .174 & .224 & .113 \\
\hline Affiliate country f.e. & NO & NO & YES & YES & YES \\
\hline BEC category of parent & All & All & All & Intermediates & Final goods \\
\hline
\end{tabular}

Errors clustered by parent in parentheses. ${ }^{* * *}, * *, *$ stand for $\mathrm{p}$-value $<0.01$, p-value $<0.05$, and p-value $<0.10$, respectively.

Apparently, the marginal effect could become negative below that threshold, where we should find only parents producing intermediate goods, i.e., midstream parents. However, the impact of demand elasticity is not significant for integrations by midstream parents in column 4 of Table 3, when we explicitly differentiate the output on the basis of the Broad Economic Categories (BEC) classification, between producers of intermediate 
and final goods. That is, the prediction of the theory in these cases is no more valid, as no statistical significance is found for the variable 'complements' and its interaction term. On the other hand, separate estimates for downstream parents for producers of final goods in column 5 report a marginal effect of 'complements' on affiliate downstreamness equal to 0.5 , which is comparable to general results in column 3 . Indeed, we find no downstream parent below this threshold.

More interestingly, we find that parents tend to integrate production stages that are proximate on the supply chain. A positive correlation exists between the downstreamness of a parent and the downstreamness of each of its integrated affiliates. Such a proximity is higher in the case of sequential complements, since the interaction term is positive. We believe that proximity on the technological sequence is probably due to the existence of economies of scope in similar technologies, ${ }^{13}$ when it is easier for a parent company to manage activities on the same segment, because they share some technological features. Conversely, it may be more costly to coordinate production stages when they are dissimilar in technology from the core activity of the company.

To the best of our knowledge, such a proximity on the supply chain in vertical integration has been neglected in previous GVCs' studies, although the possibility to integrate both backward and forward has not been excluded in previous works on vertical integration (see, for example, Acemoglu et al., 2007, and Acemoglu et al., 2010). ${ }^{14}$ From a broader perspective, our findings imply a coexistence of corporate boundaries focusing on different segments of a supply chain. Take the case of Continental AG that we describe in the introduction. The company integrated different automotive production stages over time, differentiating from original tyres and rubber manufacturing. Yet they sell to final producers of cars, trucks, and buses, located further downstream, which, in turn, can start their own backward integration choices of automotive inputs.

In Table 4 we test whether our findings are robust to different sample compositions. In the Appendix Table C4 we repeat the same exercises for midstream parents only.

Starting from the first column, we include fixed effects by country of origin to control for parent countryspecific characteristics, especially relevant in the case of multinational enterprises. We alternatively compute 'complements' as a binary variable equal to 1 when $(\rho>\alpha)$, where $\alpha$ is the median elasticity of affiliates, in the spirit of the original theoretical setups. In column 3 , we include only the top $5 \%$ of affiliates classified in terms of employment, because Ramondo et al. (2016) find that only a few large affiliates are responsible for the bulk of US intrafirm trade. In column 4, we exclude affiliates engaged in service industries, for possible errors of measurement in downstreamness. Then, we exclude affiliates from the same sector of the parent, to eliminate possible horizontal integration strategies. In column 6, we include only the top 100 inputs specific for each parent output, as from IO tables, and parents with only one primary activity, to eliminate possible cases of conglomerates. In column 7, we focus on affiliates that are more upstream than the parent, i.e., excluding the case of buyers of the parent output. In column 8, we select only affiliates integrated by the same parents, but done so after 2004. In column 9, we exclude affiliates that are indirectly controlled by the parent through other affiliates (i.e., affiliates of affiliates, see Appendix A).

Across all columns in Table 4, the role of demand elasticities is always statistically significant, but it is positive only for parents that approach the final consumers along the supply chain. In fact, the marginal effect of

\footnotetext{
13 The proximity of parents and affiliates in terms of industrial activities is consistent with findings by Alfaro and Charlton (2009). Their explanation is that many inputs can come from the same sector, even after narrow and disaggregate definitions of the latter. However, our results are robust also when we exclude affiliates from the same sector of the parent, in column 5 of Table 4.

14 At the moment, we are finalizing our paper, two works that are worth mentioning are in progress. These works may help extend the theory according also to our own findings. MengXiao (2017) models and tests the cases of firms integrating both backward and forward in a context of contractual imperfections. The author finds that excluding these cases from previous studies may bias estimates. On the other hand, Berlingieri et al. (2017) introduce technological determinants as complementary to contractual imperfections in vertical integration.
} 
the 'complements' variable is positive only for parent downstreamness that is either higher than 0.52 , which is the least conservative case in column 7 , or higher than 0.65 , which is the most conservative case in column 5.

Table 4: Variants on sample composition

\begin{tabular}{|c|c|c|c|c|c|c|c|c|c|}
\hline affiliate downstreamness $i(j) c$ & $\begin{array}{c}\text { (1) } \\
\text { parent } \\
\text { country } \\
\text { FE }\end{array}$ & $\begin{array}{c}\text { (2) } \\
\text { output \& } \\
\text { input } \\
\text { elasticiti } \\
\text { es }\end{array}$ & $\begin{array}{l}\text { top 5\% } \\
\text { affiliates }\end{array}$ & $\begin{array}{c}\text { (4) } \\
\text { only } \\
\text { manuf } \\
\text { affiliates }\end{array}$ & $\begin{array}{l}\text { different } \\
\text { sector }\end{array}$ & $\begin{array}{l}\text { top } 100 \\
\text { inputs }\end{array}$ & $\begin{array}{c}\text { (7) } \\
\text { only } \\
\text { upstream } \\
\text { to parent }\end{array}$ & $\begin{array}{l}\text { only new } \\
\text { affiliates }\end{array}$ & $\begin{array}{c}\text { (9) } \\
\text { only direct } \\
\text { control }\end{array}$ \\
\hline parent downstreamness $_{j}$ & $\begin{array}{l}.234 * * * \\
(.031)\end{array}$ & $\begin{array}{c}.231 * * * \\
(.031)\end{array}$ & $\begin{array}{c}.357 * * * \\
(.037)\end{array}$ & $\begin{array}{c}.317 * * * \\
(.034)\end{array}$ & $\begin{array}{l}.069 * * \\
(.029)\end{array}$ & $\begin{array}{c}.312 * * * \\
(.037)\end{array}$ & $\begin{array}{c}.529 * * * \\
(.030)\end{array}$ & $\begin{array}{c}.171^{* * *} \\
(.032)\end{array}$ & $\begin{array}{l}.229 * * * \\
(.039)\end{array}$ \\
\hline Complements $_{j}$ & $\begin{array}{c}-.055^{* *} \\
(.023)\end{array}$ & $\begin{array}{c}-.062 * * \\
(.025)\end{array}$ & $\begin{array}{c}-.104 * * * \\
(.031)\end{array}$ & $\begin{array}{l}-.056 * \\
(.029)\end{array}$ & $\begin{array}{c}-.082 * * * \\
(.024)\end{array}$ & $\begin{array}{l}-.061^{* *} \\
(.029)\end{array}$ & $\begin{array}{l}-.045^{*} \\
(.026)\end{array}$ & $\begin{array}{c}-.094 * * * \\
(.024)\end{array}$ & $\begin{array}{l}-.041 * \\
(.022)\end{array}$ \\
\hline $\begin{array}{l}\text { complements*parent } \\
\text { downstreamness } j_{j}\end{array}$ & $\begin{array}{c}.102 * * * \\
(.037)\end{array}$ & $\begin{array}{c}.100 * * * \\
(.038)\end{array}$ & $\begin{array}{c}.161 * * * \\
(.046)\end{array}$ & $\begin{array}{l}.094 * * \\
(.044)\end{array}$ & $\begin{array}{c}.126 * * * \\
(.038)\end{array}$ & $\begin{array}{l}.110 * * \\
(.045)\end{array}$ & $\begin{array}{l}.085 * * \\
(.042)\end{array}$ & $\begin{array}{l}.161^{* * *} \\
(.038)\end{array}$ & $\begin{array}{l}.081^{*} \\
(.046)\end{array}$ \\
\hline (log of) labor productivity $j$ & $\begin{array}{l}.008^{*} \\
(.004)\end{array}$ & $\begin{array}{c}.006 \\
(.004)\end{array}$ & $\begin{array}{c}.004 \\
(.005)\end{array}$ & $\begin{array}{l}.010 * \\
(.005)\end{array}$ & $\begin{array}{c}.001 \\
(.005)\end{array}$ & $\begin{array}{l}.008^{*} \\
(.005)\end{array}$ & $\begin{array}{l}-.000 \\
(.004)\end{array}$ & $\begin{array}{c}.009 * * * \\
(.003)\end{array}$ & $\begin{array}{l}.011^{* *} \\
(.005)\end{array}$ \\
\hline (log of) capital intensity $j$ & $\begin{array}{l}-.008 \\
(.005)\end{array}$ & $\begin{array}{l}-.007 \\
(.005)\end{array}$ & $\begin{array}{l}-.005 \\
(.005)\end{array}$ & $\begin{array}{l}-.006 \\
(.006)\end{array}$ & $\begin{array}{l}-.006 \\
(.005)\end{array}$ & $\begin{array}{l}-.009 * \\
(.006)\end{array}$ & $\begin{array}{c}-.012^{* *} \\
(.005)\end{array}$ & $\begin{array}{c}-.011 * * * \\
(.004)\end{array}$ & $\begin{array}{c}-.011^{* *} \\
(.005)\end{array}$ \\
\hline (log of) employment ${ }_{j}$ & $\begin{array}{l}.006 * * \\
(.003)\end{array}$ & $\begin{array}{l}.007 * * \\
(.003)\end{array}$ & $\begin{array}{l}.007 * * \\
(.003)\end{array}$ & $\begin{array}{c}.010 * * * \\
(.004)\end{array}$ & $\begin{array}{l}.005^{*} \\
(.003)\end{array}$ & $\begin{array}{c}.003 \\
(.003)\end{array}$ & $\begin{array}{c}.004 \\
(.003)\end{array}$ & $\begin{array}{l}.005^{*} \\
(.003)\end{array}$ & $\begin{array}{l}.008^{* *} \\
(.003)\end{array}$ \\
\hline (log of) number of affiliates $j$ & $\begin{array}{l}-.005 \\
(.003)\end{array}$ & $\begin{array}{l}-.005 \\
(.003)\end{array}$ & $\begin{array}{c}-.009 * * \\
(.004)\end{array}$ & $\begin{array}{l}-.006 \\
(.004)\end{array}$ & $\begin{array}{l}-.004 \\
(.003)\end{array}$ & $\begin{array}{l}-.004 \\
(.004)\end{array}$ & $\begin{array}{c}-.007 * * \\
(.004)\end{array}$ & $\begin{array}{c}-.007^{* *} \\
(.003)\end{array}$ & $\begin{array}{c}-.010 * * * \\
(.004)\end{array}$ \\
\hline (log of) age $j$ & $\begin{array}{l}-.003 \\
(.004)\end{array}$ & $\begin{array}{l}-.004 \\
(.004)\end{array}$ & $\begin{array}{l}-.004 \\
(.005)\end{array}$ & $\begin{array}{l}-.007 \\
(.005)\end{array}$ & $\begin{array}{c}.001 \\
(.005)\end{array}$ & $\begin{array}{l}-.005 \\
(.005)\end{array}$ & $\begin{array}{l}-.007 \\
(.005)\end{array}$ & $\begin{array}{l}-.004 \\
(.004)\end{array}$ & $\begin{array}{c}.001 \\
(.005)\end{array}$ \\
\hline multinational group $j_{j}$ & $\begin{array}{c}-.044 * * * \\
(.010)\end{array}$ & $\begin{array}{c}-.044 * * * \\
(.010)\end{array}$ & $\begin{array}{l}-.021 \\
(.013)\end{array}$ & $\begin{array}{c}-.048 * * * \\
(.011)\end{array}$ & $\begin{array}{c}-.037 * * * \\
(.011)\end{array}$ & $\begin{array}{c}-.029 * * * \\
(.011)\end{array}$ & $\begin{array}{l}-.002 \\
(.014)\end{array}$ & $\begin{array}{l}-.006 \\
(.011)\end{array}$ & $\begin{array}{l}-.014 \\
(.012)\end{array}$ \\
\hline contractibility $i$ & $\begin{array}{c}-.204 * * * \\
(.027)\end{array}$ & $\begin{array}{c}-.202 * * * \\
(.028)\end{array}$ & $\begin{array}{c}-.110 * * * \\
(.029)\end{array}$ & $\begin{array}{c}-.145 * * * \\
(.029)\end{array}$ & $\begin{array}{c}-.265 * * * \\
(.027)\end{array}$ & $\begin{array}{c}-.189 * * * \\
(0.043)\end{array}$ & $\begin{array}{c}-.083 * * * \\
(.021)\end{array}$ & $\begin{array}{c}-.207 * * * \\
(.026)\end{array}$ & $\begin{array}{c}-.188 * * * \\
(.036)\end{array}$ \\
\hline Constant & $\begin{array}{c}.758 * * * \\
(.080)\end{array}$ & $\begin{array}{c}.198 * * * \\
(.050)\end{array}$ & $\begin{array}{c}.160 * * * \\
(.050)\end{array}$ & $\begin{array}{c}.623 * * * \\
(.049)\end{array}$ & $\begin{array}{c}.767 * * * \\
(.060)\end{array}$ & $\begin{array}{c}.185^{* * *} \\
(.060)\end{array}$ & $\begin{array}{c}.501 * * * \\
(.063)\end{array}$ & $\begin{array}{c}.241^{* * * *} \\
(.051)\end{array}$ & $\begin{array}{c}.202^{* * *} \\
(.045)\end{array}$ \\
\hline Observations & 39,808 & 39,808 & 3,021 & 31,124 & 32,701 & 21,337 & 17,014 & 11,732 & 4,069 \\
\hline Adjusted R-squared & .187 & .173 & .332 & .213 & .092 & .262 & .389 & .181 & .195 \\
\hline Parent country f.e. & YES & NO & NO & NO & $\mathrm{NO}$ & NO & NO & NO & NO \\
\hline Affiliate country f.e. & YES & YES & YES & YES & YES & YES & YES & YES & YES \\
\hline
\end{tabular}

Errors clustered by parent in parentheses. ${ }^{* * *},{ }^{* *},{ }^{*}$ stand for $\mathrm{p}$-value $<0.01$, p-value $<0.05$ and $\mathrm{p}$-value $<0.10$, respectively.

Looking at similar exercises reported in Appendix Table C4, and in accordance with results reported in column 4 of Table 3, we conclude that no statistical significance exists for the role of output demand faced by the parent company when integration choices are made by midstream parents.

Across all estimates, including those in Appendix Table C4, we confirm an always positive and significant correlation between the position of the parent and its affiliates. The most conservative case from Table 4 is when we exclude affiliates from the same sector of the parent. In this case the marginal effect of parent downstreamness on affiliate downstreamness is 0.07 for sequential substitutes (when output elasticity is below the median) and 0.20 for sequential complements (when output elasticity is above the median). The least conservative case from Table 4 is when we include upstream affiliates only. In this case, marginal effects for sequential substitutes and 
sequential complements are 0.53 and 0.61 , respectively.

Among other controls, we emphasize the negative coefficient that is always present on affiliate-level contractibility, which implies that upstream suppliers are, on average, more contractible. In Section 4.3 we will explicitly and positively test for asymmetries in contractibilities, following the generalization in theory by Alfaro et al. (2015). In that case, we find that parents prefer integrating in the direction in which stages are more contractible.

Finally, in Table 5, we check if results are still valid when introducing control groups for firms that were initially excluded from our sample (See Section 3.1 and Appendix A for details).

Table 5: Control groups

\begin{tabular}{|c|c|c|c|}
\hline $\begin{array}{l}\text { Dependent variable: } \\
\text { affiliate downstreamness } i(j) c\end{array}$ & $\begin{array}{l}\text { (1) } \\
\text { non-manuf } \\
\text { parents }\end{array}$ & $\begin{array}{c}\text { (2) } \\
\text { portfolio } \\
\text { investment }\end{array}$ & $\begin{array}{l}\text { (3) } \\
\text { no integration in } \\
\text { 2004-2012 }\end{array}$ \\
\hline parent downstreamness $_{j}$ & $\begin{array}{c}.286 * * * \\
(.031)\end{array}$ & $\begin{array}{c}.126 * * * \\
(.027)\end{array}$ & $\begin{array}{c}.468 * * * \\
(.035)\end{array}$ \\
\hline complements $_{j}$ & $\begin{array}{l}-.006 \\
(.023)\end{array}$ & $\begin{array}{l}-.015 \\
(.020)\end{array}$ & $\begin{array}{l}-.031 \\
(.028)\end{array}$ \\
\hline complements* parent downstreamness ${ }_{j}$ & $\begin{array}{c}.025 \\
(.037)\end{array}$ & $\begin{array}{c}.028 \\
(.032)\end{array}$ & $\begin{array}{c}.067 \\
(.041)\end{array}$ \\
\hline (log of) labor productivity $j$ & $\begin{array}{l}-.003 \\
(.003)\end{array}$ & $\begin{array}{l}-.003 \\
(.004)\end{array}$ & $\begin{array}{l}-.004 \\
(.004)\end{array}$ \\
\hline (log of) capital intensity $j$ & $\begin{array}{l}-.003 \\
(.002)\end{array}$ & $\begin{array}{c}.006 \\
(.003)\end{array}$ & $\begin{array}{c}-.005^{*} \\
(.002)\end{array}$ \\
\hline (log of) employment $j$ & $\begin{array}{c}.001 \\
(.002)\end{array}$ & $\begin{array}{c}.001 \\
(.002)\end{array}$ & $\begin{array}{l}.005^{* *} \\
(.002)\end{array}$ \\
\hline (log of) number of affiliates $j$ & $\begin{array}{l}-.003 * \\
(.002)\end{array}$ & $\begin{array}{c}.002 \\
(.003)\end{array}$ & $\begin{array}{l}-.006 \\
(.004)\end{array}$ \\
\hline$(\log$ of) age $j$ & $\begin{array}{l}.006^{*} \\
(.003)\end{array}$ & $\begin{array}{l}-.003 \\
(.004)\end{array}$ & $\begin{array}{l}-.004 \\
(.003)\end{array}$ \\
\hline multinational group $j_{j}$ & $\begin{array}{c}-.017 * * * \\
(.006)\end{array}$ & $\begin{array}{c}.006 \\
(.014)\end{array}$ & $\begin{array}{l}-.001 \\
(.007)\end{array}$ \\
\hline contractibility $i$ & $\begin{array}{c}-.220 * * * \\
(.020)\end{array}$ & $\begin{array}{c}-259 * * * \\
(.022)\end{array}$ & $\begin{array}{c}-.158 * * * \\
(.020)\end{array}$ \\
\hline Constant & $\begin{array}{c}.655^{* * *} \\
(.028)\end{array}$ & $\begin{array}{c}.871^{* * *} \\
(.041)\end{array}$ & $\begin{array}{c}-328 * * * \\
(.045)\end{array}$ \\
\hline Observations & 72,628 & 20,991 & 110,104 \\
\hline Adjusted R-squared & .166 & .087 & .360 \\
\hline Affiliate country f.e. & YES & YES & YES \\
\hline
\end{tabular}

As expected, the 'complements' variable, alone and in interaction, is no longer significant in the cases of (1) service parents, since they may include firms that are not integrating affiliates for the organization of GVCs (e.g., financial companies, utilities, consultancy firms, etc.); (2) portfolio investment operations, when manufacturing parent companies have only a minority stake, because the company's interest may not be in the coordination of that production stage; (3) manufacturing parents that never integrated after 2004, which is the 
period for which we have both metrics for determinants and firm-level controls. In the latter case, simultaneity/endogeneity bias may be present for tests against ex post regressors. Nonetheless, a correlation between positions of a parent and its affiliates persists in all cases.

\subsection{Relative downstreamness}

In this section and the next we will make use of a more recent measure for positioning along the value chain developed by Alfaro et al. (2015). The new indicator originally measures Relative Upstreamness of an $m$ th input, with respect to the $n$th output, based on 1992 U.S. I-O Tables.

For our scope, this measure is complementary to the Absolute Downstreamness we have used in previous estimates. It is very useful, because it abandons the strong assumption of a unique technological sequence for all outputs, catching the technological distance between any two industries that have an input-output relationship, thereby making the technological distance specific and oriented toward each output. In other words, each output now has an upstream technological sequence, with inputs located at varying distances.

However, this means that the orientation to final demand is lost and an arbitrary nth output can be just another intermediate stage, either a part or a component, used further downstream by either another intermediate or a final producer. That is, the Relative Upstreamness may measure the distance between two intermediate stages of production, once assuming that one sources from the other. From our point of view, this measure better proxies a proximity between outputs and inputs, rather than the distance of production stages from final consumers.

Relative Upstreamness originally ranges in an interval $(0,+\infty)$, such that a higher level of the $m$ th input, given the $n$th output, implies that the two industries are more distant. For the sake of comparison with previous analyses, we consider its inverse, hence falling in a standardized range $(0,1)$. In this case, a higher level of Relative Downstreamness of the $m$ th input implies that the latter is more proximate to the $n$th output.

After matching with parent and affiliate data on industries, we can now consider the Relative Downstreamness of an affiliate with respect to its parent as a dependent variable in the following equation:

$$
Y_{i(j) c}=\beta_{0}+\beta_{1} \rho_{j}^{*}+\beta_{2} Z_{j}+\beta_{3} W_{i}+\beta_{6} V_{c}+\varepsilon_{i(j) c}
$$

where any ith affiliate producing an $m$ th input is integrated by the $j$ th parent producing the $n$th output. In this case, we do not need to introduce the position of the parent company as a further covariate, because this information is already part of the dependent variable $Y_{i(j) c}$. Moreover, $Z_{j}, W_{i}$ and $V_{c}$ collect parent, affiliate and country controls, respectively, as in eq. (1). Nested results are reported in Table 6.

Also in this case, results confirm the main theoretical prediction, according to which, if downstream parent companies face a sufficiently elastic demand, they tend to own suppliers located relatively close to their final output, as shown in column 3.

In the case of midstream parents, a reversal of sign is instead detected for the 'complements' variable. Apparently, a negative and significant correlation between proximity on the technological sequence and elasticity of substitution when a parent produces intermediate inputs is here revealed. Unfortunately, in the case of midstream parents, nothing can be said about either the nature of this correlation or the role of demand elasticity from existing theory. The use of Relative Downstreamness ${ }^{15}$ prevents us from making reference to distance from final demand,

\footnotetext{
15 Please note that, by construction, the relative upstreamness/downstreamness requires an ex ante assumption on the orientation
} 
as from existing theory. Rather, we refer to results obtained in column 4 of Table 3, where no statistical significance is observed for the role of demand elasticity.

Table 6: Relative downstreamness

\begin{tabular}{|c|c|c|c|}
\hline Dependent variable: & (1) & (2) & (3) \\
\hline relative downstreamness of affiliate $i(j) c$ & $\begin{array}{l}\text { OLS, firm } \\
\text { controls \& fe }\end{array}$ & $\begin{array}{l}\text { OLS, firm } \\
\text { controls \& fe }\end{array}$ & $\begin{array}{l}\text { OLS, firm } \\
\text { controls \& fe }\end{array}$ \\
\hline \multirow[t]{2}{*}{ complements $_{j}$} & -.014 & $-.079 * * *$ & $.051 * * *$ \\
\hline & $(.013)$ & $(.015)$ & $(.018)$ \\
\hline \multirow[t]{2}{*}{ (log of) labor productivity $j$} & $.021 * *$ & -.016 & $.030 * *$ \\
\hline & $(.010)$ & $(.013)$ & $(.015)$ \\
\hline \multirow[t]{2}{*}{ (log of) capital intensity $j$} & $.016 *$ & $.034^{* * *}$ & .009 \\
\hline & $(.009)$ & $(.011)$ & $(.014)$ \\
\hline \multirow[t]{2}{*}{ (log of) employment ${ }_{j}$} & $.012 * *$ & .003 & .013 \\
\hline & $(.006)$ & $(.005)$ & $(.008)$ \\
\hline \multirow[t]{2}{*}{ (log of) number of affiliates $j$} & $-.015 * * *$ & -.001 & $-.019 * *$ \\
\hline & $(.006)$ & $(.006)$ & $(.008)$ \\
\hline \multirow[t]{2}{*}{$(\log$ of) age $j$} & -.010 & -.005 & -.014 \\
\hline & $(.007)$ & $(.006)$ & $(.012)$ \\
\hline \multirow[t]{2}{*}{ multinational group $j_{j}$} & $-.066 * * *$ & $-.049 *$ & $-.079 * *$ \\
\hline & $(.021)$ & $(.027)$ & $(.031)$ \\
\hline \multirow[t]{2}{*}{ contractibility $i$} & -.036 & $.064 *$ & $-.154 * *$ \\
\hline & $(.032)$ & $(.033)$ & $(.075)$ \\
\hline \multirow[t]{2}{*}{ Constant } & $.247 * * *$ & $.356 * * *$ & $.721^{* * *}$ \\
\hline & $(.073)$ & $(.066)$ & (.089) \\
\hline Observations & 18,902 & 9,259 & 9,643 \\
\hline Adjusted R-squared & .055 & .093 & .086 \\
\hline Affiliate country f.e. & YES & YES & YES \\
\hline BEC category of parent & All & Intermediates & Final goods \\
\hline
\end{tabular}

\subsection{Non-integrated stages}

Finally, we control whether our results are robust when we explicitly consider production stages that were never integrated. In fact, until now, we tested integration by only observing ex post which affiliates and industries a parent company chose to integrate. In other words, in absence of data on external suppliers, we relied on data for integrated affiliates.

Now, we modify our data structure, in line with Alfaro et al. (2015), to consider also the production stages

between an $m$ th industry and an $n$th industry, as to which is the input and which is the output. Once matching the metrics with parentaffiliate data, we implicitly assume that the output is produced by the parent and its affiliates are possible upstream suppliers (never buyers). In this, the 'absolute downstreamness' allows us more flexibility for including cases of forward integration by parents. 
that could have been possibly integrated, but which, eventually, were not. We lose the parent and affiliate level dimension to switch to a parent-industry dimension. Our unit of observation is now a pair made of a parent company (taken with its output) and any possible input industry, as derived from input-output tables. ${ }^{16}$

We test a conditional logit model ${ }^{17}$ with parent-level fixed effects, in the following equation:

$$
I N T_{m j}=\beta_{0}+\beta_{1} r e l_{m j}+\beta_{2} \rho_{j}^{*}+\beta_{3}\left(\operatorname{rel}_{m j} \cdot \rho_{j}^{*}\right)+\beta_{4} u p t o_{m j}+\beta_{5}\left(u p t o_{m j} \cdot \rho_{j}^{*}\right)+\beta_{6} N_{j}+\eta_{j}+\varepsilon_{m j}
$$

where $I N T_{m j}$ is a binary variable equal to one when the parent $j$ has integrated at least one affiliate active in the input industry $m$. If the parent has not integrated any affiliate in the input industry, that input is assumed to be outsourced. Among regressors, $r_{m j}$ is the $m$ th input's Relative Downstreamness of parent $j$ active in the nth industry. $\rho_{j}^{*}$ is a binary variable that takes the value 1 for sequential complements, when elasticity of output is above the median of all inputs, either integrated or not integrated by a parent firm $\left(\rho>\rho_{\text {med }}\right)$, and 0 for sequential substitutes, when elasticity of output is below the median $\left(\rho<\rho_{\text {med }}\right)$. The variable upto $_{\text {mj }}$ is the cumulative contractibility for all the ordered upstream stages included up to the $m$ th input, as in Alfaro et al. (2015). $N_{j}$ is a binary variable that is equal to one if the input belongs to the same industry as the parent. Finally, we introduce a full set of parent-level fixed effects $\left(\eta_{j}\right)$. Predicted probabilities for nested specifications are reported in Table 7 .

Firstly, the results confirm that an input is more likely integrated if it is proximate to the parent output along the technological sequence, possibly due to some shared economies of scope in technologies. ${ }^{18}$

Secondly, the role of demand elasticity is found to be significant overall, but this result is no longer valid in the case of downstream parents when we introduce a measure of cumulate contractibility up to the input $m$ (Table 7, column 6). This is in line with what was found by Alfaro et al. (2015). That is, asymmetries in contractibility along the technological sequence can be a further determinant of integration choices. In this framework, a greater degree of contractibility of upstream inputs increases the propensity of a firm to integrate in that direction, where input $m$ can be found.

Note how these findings are also consistent with previous estimates, starting from baseline in Table 3, where we find that (integrated) upstream suppliers are, on average, more contractible.

Unfortunately, nothing can be said about the role of elasticity of demand for midstream parents and their direction of integration, since the use of Relative Downstreamness prevents us from making reference to distance from final demand, as from existing theory. See also the comments to results in Table 6.

Table 7: Fixed effects conditional logit - integrated and non-integrated stages

\footnotetext{
${ }^{16}$ In line with Alfaro et al. (2015), we select the top 100 inputs for each output, as from coefficients of I-O tables. In this way, we exclude possible activities that are loosely related to the output of the parent, as in the case of conglomerates, for example. On average, a representative parent integrates 3 input industries out of the top 100. In Appendix Table C5, we further test whether the inclusion of both primary and secondary activities at the parent level and affiliate level, as originally done by Alfaro et al. (2015), does not change our results. There, the parent integrates an average of 4 input industries out of the top 100. Results are similar in magnitude and statistical significance.

17 Results are robust to different specifications, including the linear probability model originally tested by Alfaro et al. (2015), the probit model, and the logit model. These results are available upon request. We report findings of the conditional logit, because it fits better the multinomial case of ex ante alternatives. See McFadden (1974) and Head et al. (1995) for an application.

18 Please note the change in the interpretation of coefficients. In the case of simple downstreamness, a correlation between a parent and an affiliate reveals an ex post proximity on the supply chain, as in Section 4.1 and 4.2. After the adoption of a conditional logit model, relative downstreamness reveals a positive and significant probability that (industries of) a parent and (industries of) its affiliates are proximate.
} 
Dependent variable:

(1)

(2)

(3)

(4)

(5)

(6)

Input $m$ integrated by parent $j$ (Yes/No)

\begin{tabular}{|c|c|c|c|c|c|c|}
\hline relative downstreamness $m j$ & $\begin{array}{c}.445 * * * \\
(.015)\end{array}$ & $\begin{array}{c}.444^{* * *} \\
(.019)\end{array}$ & $\begin{array}{c}.383^{* * *} \\
(.027)\end{array}$ & $\begin{array}{c}.455^{* * *} \\
(.021)\end{array}$ & $\begin{array}{c}.421^{* * *} \\
(.030)\end{array}$ & $\begin{array}{c}.430 * * * \\
(.034)\end{array}$ \\
\hline complements*relative downstreamness $m j$ & $\begin{array}{c}.120 * * * \\
(.022)\end{array}$ & $\begin{array}{c}.155^{* * *} \\
(.029)\end{array}$ & $\begin{array}{c}.166^{* * *} \\
(.039)\end{array}$ & $\begin{array}{l}.069 * * \\
(.030)\end{array}$ & $\begin{array}{c}.156^{* * *} \\
(.043)\end{array}$ & $\begin{array}{c}.065 \\
(.050)\end{array}$ \\
\hline contractibility up-to-input $m j$ & & & & $\begin{array}{c}.013 * * * \\
(.003)\end{array}$ & $\begin{array}{c}.017 * * * \\
(.004)\end{array}$ & $\begin{array}{c}.007 \\
(.005)\end{array}$ \\
\hline contractibility up-to-input* ${ }^{*}$ complements $m j$ & & & & $\begin{array}{l}.007^{*} \\
(.004)\end{array}$ & $\begin{array}{l}-.001 \\
(.005)\end{array}$ & $\begin{array}{l}.016^{* *} \\
(.007)\end{array}$ \\
\hline Dummy: Self-NAICS $m j$ & $\begin{array}{c}.654^{* * *} \\
(.013)\end{array}$ & $\begin{array}{c}.602 * * * \\
(.018)\end{array}$ & $\begin{array}{c}.740 * * * \\
(.022)\end{array}$ & $\begin{array}{c}.708^{* * *} \\
(.016)\end{array}$ & $\begin{array}{c}.671^{* * *} \\
(.022)\end{array}$ & $\begin{array}{c}.770^{* * *} \\
(.025)\end{array}$ \\
\hline Observations (parent per stage) & 258,513 & 123,692 & 101,082 & 241,378 & 116,239 & 93,910 \\
\hline Pseudo R-squared (McFadden's) & .181 & .179 & .186 & .189 & .183 & .198 \\
\hline Parent-level f.e. & YES & YES & YES & YES & YES & YES \\
\hline BEC category of parent & All & Intermediates & Final goods & All & Intermediates & Final goods \\
\hline
\end{tabular}

Robust standard errors in parentheses. ${ }^{* * *}, * *, *$ stand for p-value $<0.01$, p-value $<0.05$ and p-value $<0.10$, respectively.

\section{Conclusions}

Assuming a technological sequence of ordered inputs leading to a final output, recent theory predicts that decisions of (backward) integration are based crucially on the role of demand elasticity of the final producer, in the presence of contractual imperfections,

On the one hand, we provide empirical evidence at the parent and affiliate level that supports the main theoretical prediction (Antràs and Chor, 2013; Alfaro et al., 2015), according to which producers of final goods engage in (backward) vertical integration, preferably more downstream, when the elasticity of final output is sufficiently high. On the other hand, we argue that cases of midstream parents are neglected by existing works on GVCs. The latter are companies that specialize in intermediate inputs, possibly integrating both backward and forward suppliers, starting from the middle of the supply chain. We report that they are at least as common as are cases of downstream parents. We may think of many real-world cases of companies that specialize in intermediate inputs and do not direcly sell to final consumers. In these cases, we detect no significant role for demand elasticities as drivers of integration choices.

Instead, we find that both downstream and midstream parents systematically prefer to integrate production stages that are proximate along segments of the supply chain. Our findings point to an important role played by technological determinants, which may be as important as contracting frictions in shaping firm-level organization of GVCs. In fact, we presume that it is less costly to coordinate production stages from headquarters when these stages share some technological characteristics, while sourcing dissimilar stages from arm's length suppliers.

We believe that exploring technological complementarities among suppliers on a technological sequence is both a theoretical and an empirical challenge for future works, which would help to better understand patterns of vertical integration within and across national borders.

\section{Acknowledgements}


We would like to thank Pol Antràs, Laura Alfaro, Davin Chor, Paola Conconi, Daniel Trefler, Joanne Oxley, Kunal Dasgupta, Gianmarco Ottaviano, Dalia Marin, Carlo Altomonte, Giorgia Giovannetti, Anna Giunta, Giuseppe De Arcangelis, and Pierluigi Montalbano, in addition to participants at the 'WB/CEPR Second Conference on Global Value Chains, Trade and Development 2016', 'Royal Economic Society 2016', 'Warsaw International Economic Meeting 2015’, 'European Trade Study Group 2014’, 'Explaining Economic Change 2014 - Rome’, and also at various seminars, for useful comments. The authors claim financial support by CrisisLab PNR Project at IMT School for Advanced Studies, Lucca.

\section{References}

Acemoglu, D., P. Antràs, and E. Helpman (2007). "Contracts and Technology Adoption". American Economic Review 97(3), 916-943.

Acemoglu, D., R. Griffith, P. Aghion, and F. Zilibotti (2010). "Vertical integration and technology: theory and evidence". Journal of the european economic Association 8(5), 989-1033.

Acemoglu, D., S. Johnson, and T. Mitton (2009). "Determinants of vertical integration: financial development and contracting costs". The Journal of Finance 64(3), 1251-1290.

Aghion, P. and R. Holden (2011). "Incomplete contracts and the theory of the firm: What have we learned over the past 25 years?". The Journal of Economic Perspectives 25(2), 181-197.

Alfaro, L., P. Antràs, D. Chor, and P. Conconi (2015). "Internalizing Global Value Chains: A Firm-Level Analysis". NBER Working Paper No. w21582.

Alfaro, L. and A. Charlton (2009). "Intra-industry Foreign Direct Investment". American Economic Review 99(5), 2096-2119.

Alfaro, L., P. Conconi, H. Fadinger, and A. Newman (2016). "Do Price Determine Vertical Integration?". Review of Economic Studies 83, 1-35.

Altomonte, C. and A. Rungi (2013). "Business Groups as Hierarchies of firms: Determinants of Vertical Integration and Performance ". ECB Working Paper No. 1554.

Alviarez, V., J. Cravino, and A. A, Levchenko (2016). "The Growth of Multinational Firms in the Great Recession". Journal of Monetary Economics 85, 50-64.

Antràs, P. (2003). "Firms, Contracts, And Trade Structure". The Quarterly Journal of Economics 118(4), 1375-1418.

Antràs, P. and D. Chor (2013). "Organizing the Global Value Chain". Econometrica 81(6), 2127-2204.

Antràs, P., D. Chor, T. Fally, and R. Hillberry (2012). "Measuring the Upstreamness of Production and 
Trade Flows". The American Economic Review 102(3), 412-416.

Antràs, P. and E. Helpman (2004). "Global Sourcing". Journal of Political Economy 112(3), 552-580.

Antràs, P. and S. Yeaple (2014). "Multinational Firms and the Structure of International Trade". Handbook of International Economics 4(55).

Baldwin, R. and J. Lopez-Gonzalez (2014). "Supply-chain Trade: A Portrait of Global Patterns and Several Testable Hypotheses". The World Economy.

Berlingieri, G., F. Pisch, and C. Steinwender (2017). "Technological Determinants of the Make-Or-Buy Decision". Mimeo.

Blomström, M. and R. E. Lipsey (1991). "Firm size and foreign operations of multinationals". The Scandinavian Journal of Economics, 101-107.

Broda, C. and D. Weinstein (2006). "Globalization and the Gains From Variety". Quarterly Journal of Economics 121(2), 541-585.

Coase, R. H. (1937). "The nature of the firm". Economica 4(16), 386-405.

Corcos, G., D. M. Irac, G. Mion, and T. Verdier (2013). "The determinants of intrafirm trade: Evidence from French firms". Review of Economics and Statistics 95(3), 825-838.

Costinot, A., J. Vogel, and S. Wang (2013). "An elementary theory of global supply chains". The Review of Economic Studies 80(1), 109-144.

Cravino, J. and A. A. Levchenko (2016). "Multinational Firms and International Business Cycle Transmission". The Quarterly Journal of Economics, forthcoming.

Fan, J. P. H. and L. H. P. Lang (2000). "The measurement of relatedness: An application to corporate diversification". The Journal of Business 73(4), 629-660.

Greenaway, D. and R. Kneller (2007). "Industry differences in the effect of export market entry: learning by exporting?". Review of World Economics 143(3), 416-432.

Grossman, S. J. and O. D. Hart (1986). "The Costs and Benefits of Ownership: A Theory of Vertical and Lateral Integration". Journal of Political Economy 94(4), 691.

Harms, P., O. Lorz, and D. Urban (2012). "Offshoring along the production chain". Canadian Journal of Economics/Revue canadienne d'économique 45(1), 93-106.

Head, K., J. Ries, and D. Swenson (1995). “Agglomeration Benefits and Location Choice: Evidence from Japanese Manufacturing Investments in the United States”. Journal of International Economics 38 (3-4), 223-247. 
Helpman, E., M. Melitz, and S. Yeaple (2004). "Export versus FDI with heterogeneous firms". American Economic Review 94.

Hummels, D., J. Ishii, and Kei-mu. Yi (2001). "The nature and growth of vertical specialization in world trade". Journal of International Economics 54, 75-96.

Kaufmann, D., A. Kraay, and M. Mastruzzi (2011). "The worldwide governance indicators: methodology and analytical issues". Hague Journal on the Rule of Law 3(02), 220-246.

MengXiao, L. (2016). "Global Supply Chains without Principals". Mimeo.

McFadden, D. (1974). “Conditional Logit Analysis of Qualitative Choice Behavior”. In Frontiers in Econometrics, New York:Academic Press

Nunn, N. (2007). "Relationship-specificity, incomplete contracts, and the pattern of trade". Quarterly Journal of Economics 122(2), 569-600.

Nunn, N. and D. Trefler (2008). "The Boundaries of the Multinational Firm: An Empirical Analysis". In E. Helpman, D. Marin, and T. Verdier (Eds.), The Organization of Firms in a Global Economy. Cambridge University Press.

OECD (2005). "Guidelines for Multinational Enterprises". OECD, Paris.

Pierce, J. and P. Schott (2012). "A concordance between ten-digit US Harmonized System Codes and SIC/NAICS product classes and industries". Journal of Economic and Social Measurement 37(1), 61-96.

Ramondo, N., V. Rappoport, and K. J. Ruhl (2016). "Intrafirm trade and vertical fragmentation in US multinational corporations". Journal of International Economics 98, 51-59.

Rauch, J. E. (1999). "Networks versus markets in international trade". Journal of International Economics 48(1), 7-35.

Rungi, A., G. Morrison, and F. Pammolli (2016). "Corporate boundaries of Multinaltional Enterprises: a network approach". EIC working paper series IMT Institute for Advanced Studies Lucca.

UNCTAD (2009). "Training Manual on Statistics for FDI and the Operations of TNCs Vol. II.". United Nations.

UNCTAD (2016). "World Investment Report 2016". United Nations.

Williamson, O. E. (1971). "The vertical integration of production: market failure considerations". The American Economic Review 61(2), 112-123.

Williamson, O. E. (1975). "Markets and hierarchies". New York, 26-30. 
Williamson, O. E. (1979). "Transaction-cost economics: the governance of contractual relations". The journal of law \& economics 22(2), 233-261.

World-Bank (2015). "World Development Indicators". The World Bank.

\section{A - Appendix: Corporate boundaries}


Data come from ORBIS and ZEPHYR, two large cross-country databases maintained by Bureau van Dijk. The ORBIS database includes information on financial accounts and ownership. ORBIS is integrated with ZEPHYR, which collects information on M\&A deals. They both source original information from several national registries and international providers. For our scope, ORBIS permits the identification of an ultimate owner and its links with affiliates around the world. We specify that the ultimate owner should be a parent owning at least $50 \%$ of an affiliate. We keep companies in which parents have a minority stake as a first control group for robustness checks later in the analyses. We exclude from our sample all stand-alone firms, which do not have a parent company and may be owned by individuals. Eventually, our definition of corporate boundaries is the same as that acknowledged in international standards, see, for example, UNCTAD (2016), following the algorithm by Rungi et al. (2016), but also OECD (2005) and UNCTAD (2009) as manuals for statistics on multinational enterprises. See also Cravino and Levchenko (2016), Alviarez et al. (2016) and Altomonte and Rungi (2013), for a similar use of Orbis data.

In Figure A1, we briefly describe a fictional corporate boundary, which may be present in our sample.

Figure A1: Corporate boundaries

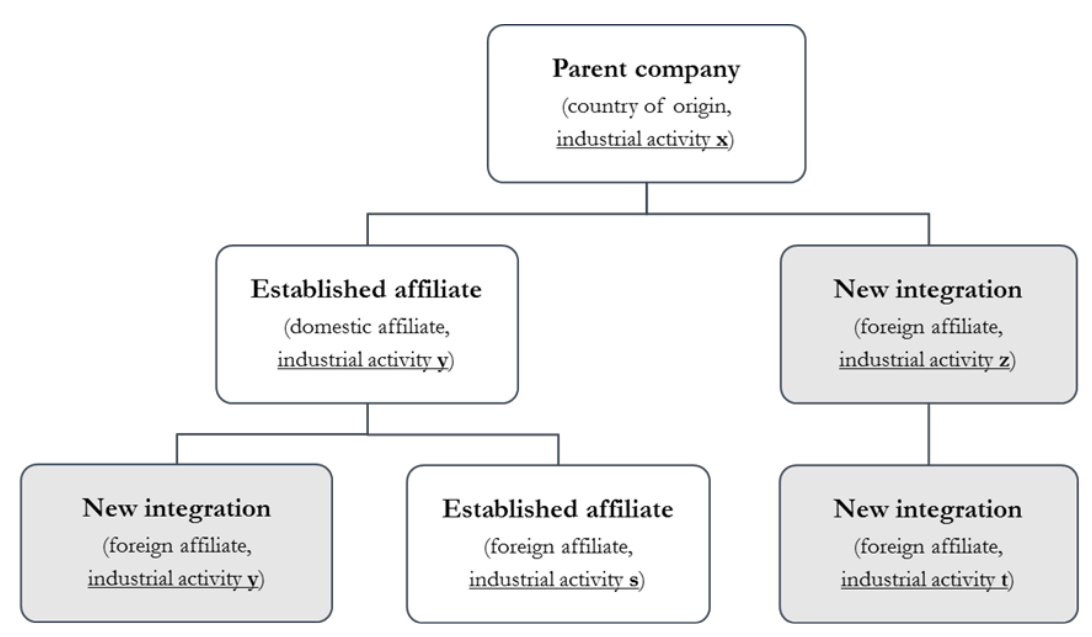

The parent on top directly controls two affiliates and, thanks to this, indirectly controls three other affiliates. That is, in Figure A1, three firms can be considered as 'affiliates of affiliates', located on different hierarchical levels. Based on information on M\&A deals from ZEPHYR and dates of incorporation from ORBIS, we can virtually separate new and past integration choices. In fact, in Figure A1, white boxes indicate affiliates that were already integrated before the new integrations occurred. We exclude from our sample parent companies that never integrated any affiliate in 2004-2012, for which we have information on metrics for determinants of integration and firm-level controls. The inclusion of the latter may induce a simultaneity bias in estimates with ex post regressors. We keep these as a second control group for later robustness checks.

For both parents and affiliates, we have information on the country and on the 6-digit primary industries (NAICS rev. 2007) in which it operates. To distinguish between domestic and foreign affiliates, we consider the country of the parent company as the origin of the entire group. We further assume that the primary activity of the parent defines the main output of the group, whereas primary activities of the affiliates are its inputs. However, it is possible that either parents or affiliates may report more than one primary activity, which is consistent with the conglomerate nature of some companies. Throughout the analyses, we perform different robustness checks for the 
validity of assumptions based on the idenfication of industries. We exclude from our sample non-manufacturing parents (but we keep service affiliates), which may be not interested in the organization of GVCs (i.e., financial companies, utilities, consultancy firms, etc.). We keep them as a third control group for robustness checks later in the analyses.

Originally we find 284,628 parent companies controlling more than 1 million and a half affiliates at the end of 2012. Among these, only 47,631 have primary manufacturing activities. In 2004-2012, there were 32,470 parent companies that reportedly integrated at least one further affiliate. Of these, only 4,192 are manufacturing parents, controlling 90,298 affiliates for which we have complete information on the countries and the industries in which they operate. They integrated 28,638 new affiliates in 2004-2012.

\section{B - Appendix Data}


Absolute and Relative Downstreamness. The Absolute Downstreamness is sourced from Antràs and Chor (2013). They propose two alternative metrics based on 2002 U.S. I-O Tables. The first is the ratio of the aggregate direct use to the aggregate total use (DUseTUse) of a particular industry i's goods, where the direct use for a pair of industries is the value of goods from industry $i$ directly used by firms in industry $j$ to produce final goods, while the total use is the value of goods from industry $i$ used, either directly or indirectly, in producing industry $j$ 's output for final goods. Thus, a high value of DUseTUse suggests that most of the contribution of input $i$ tends to occur relatively downstream, close to final demand. The second measure (DownMeasure) introduces a penalty, or a weight, for the average position at which an industry's output is used.

We also make use of the more recent Relative Upstreamness, sourced from Alfaro et al. (2015), which is a weighted-average of the number of stages it takes for input $i$ to enter in the production of $j$, where the weights correspond to the share of total requirements' coefficients $i j$ that enters at the corresponding upstream stage of production. For the sake of comparision across metrics, we take the inverse of Relative Upstreamness, such that a larger Relative Downstreamness means that a greater share of the total input use value of $i$ is accrued closer in the production process for $j$.

Demand Elasticity. This is sourced from Broda and Weinstein (2006). We convert from HS10 codes, using tables provided by Pierce and Schott (2012). Following Antràs and Chor (2013), we identify industries that have elasticity above the median (5.37 for the 437 manufacturing sectors present in our data) as sequential complements and industries below the median as sequential substitutes. In a robustness check, we alternatively identify sequential complements $(\rho-\alpha)$ as being those cases in which the ratio between the elasticity faced by the parent company and the median value of the elasticity faced by the affiliates $(\rho / \alpha)$ is higher than unity.

Capital intensity. This is computed at the parent level from our sample, sourced from the Orbis database. It is a ratio between fixed assets and number of employees.

Age. This is computed at the parent level from our sample, sourced from the Orbis database. It is the age since incorporation of the company and until when choices of integration were undertaken.

Size. This is computed at the parent level from our sample, sourced from the Orbis database. It is the number of (consolidated) employees.

Productivity. This is computed at parent-level from our sample, sourced from the Orbis database. It is the ratio between value added and number of employees.

Number of affiliates. This is computed at the parent level from our sample, sourced from the Orbis database. It is the number of affiliates in which the parent has a (direct or indirect) majority stake.

Multinational Group. This is computed at the parent level from our sample, sourced from the Orbis database. It is a binary variable equal to 1 if the parent owns at least one foreign affiliate, i.e., in a country diffent from that of origin.

Contractibility. This is computed at the industry level and then matched with the 6-digit industries of the affiliates. It is sourced from Antràs and Chor (2013), who computed the measure from the 2002 U.S. I-O Tables, following the methodology of Nunn (2007) and Rauch (1999). 
Entry cost. This is sourced from the World Bank - Doing Business (World Bank, 2015). It is built on the number of procedures, number of days, and cost (as a percentage of income per capita) required to start a business in a country. We averaged over 2003-2005 for each affiliate $i$ and host country $c$.

Rule of law. This is sourced from the Worldwide Governance Indicators (Kaufmann et al., 2011). The annual index is linearly rescaled from its original range [-2.5, 2.5], to lie in a range [0,1], and averaged over 20042010 for each affiliate's country of origin $c$. This index reflects perceptions in terms of the extent to which agents both have confidence in and abide by the rules of society, especially in the quality of contract enforcement, property rights, the role of police and courts, and the likelihood of crime and violence. 


\section{C - Appendix Tables}

Table C1: Highest and lowest values of absolute downstreamness from sample

\begin{tabular}{|c|c|c|}
\hline NAICS & Industry Label & Downstreamness \\
\hline \multicolumn{3}{|c|}{$\underline{\text { Lowest } 10 \text { values }}$} \\
\hline 331314 & Secondary Smelting and Alloying of Aluminum & 0.0000 \\
\hline 325110 & Petrochemical Manufacturing & 0.0599 \\
\hline 331411 & Primary Smelting and Refining of Copper & 0.0741 \\
\hline 336112 & Light Truck and Utility Vehicle Manufacturing & 0.0814 \\
\hline 325211 & Electric Housewares and Household Fan Man. & 0.1205 \\
\hline 325910 & Printing Ink Manufacturing & 0.1325 \\
\hline 311119 & Other Animal Food Manufacturing & 0.1385 \\
\hline 333220 & Plastics and Rubber Industry Machinery Man. & 0.1420 \\
\hline 331311 & Alumina Refining & 0.1447 \\
\hline 331312 & Primary Aluminum Production & 0.1447 \\
\hline \multicolumn{3}{|c|}{$\underline{\text { Highest } 10 \text { values }}$} \\
\hline 337122 & Nonupholstered Wood Household Furniture Man. & 0.9922 \\
\hline 339116 & Dental Laboratories & 0.9942 \\
\hline 332992 & Small Arms Ammunition Manufacturing & 0.9956 \\
\hline 332993 & Ammunition (except Small Arms) Man. & 0.9956 \\
\hline 316211 & Rubber and Plastics Footwear Man. & 0.9967 \\
\hline 316212 & House Slipper Manufacturing & 0.9967 \\
\hline 316213 & Men's Footwear (except Athletic) Man. & 0.9967 \\
\hline 316214 & Women's Footwear (except Athletic) Man. & 0.9967 \\
\hline 316219 & Other Footwear Manufacturing & 0.9967 \\
\hline 336111 & Automobile Manufacturing & 0.9997 \\
\hline
\end{tabular}


Table C2: Descriptive statistics of firm, industry and country controls

\begin{tabular}{|c|c|c|c|c|c|c|}
\hline & Obs. & Mean & Median & St. dev. & Min & Max \\
\hline \multicolumn{7}{|l|}{ Parents } \\
\hline (Log of) labor productivity & 2,425 & 4.32 & 4.43 & 1.1 & -3.82 & 11.72 \\
\hline (Log of) capital intensity & 2,608 & 4.89 & 4.92 & 1.28 & -3.18 & 12.02 \\
\hline (Log of) size & 3,121 & 6.81 & 6.83 & 2.34 & 0 & 12.81 \\
\hline (Log of) Age & 4,121 & 3.25 & 3.22 & .9 & 0 & 5.9 \\
\hline (Log of) Number of affiliates & 4,192 & 2.63 & 2.4 & 1.78 & 0 & 6.91 \\
\hline Multinational Group & 4,192 & .64 & 1 & .48 & 0 & 1 \\
\hline \multicolumn{7}{|l|}{ Global Parents only } \\
\hline (Log of) labor productivity & 1,757 & 4.47 & 4.52 & .99 & -3.30 & 11.72 \\
\hline (Log of) capital intensity & 1,857 & 5.09 & 5.06 & 1.13 & -3.18 & 12.02 \\
\hline (Log of) size & 2,094 & 7.55 & 7.65 & 2.15 & 0 & 12.81 \\
\hline (Log of) Age & 2,675 & 3.28 & 3.18 & 1.75 & 0 & 6.91 \\
\hline (Log of) Number of affiliates & 2,615 & 3.40 & 3.37 & 0.91 & 0 & 5.90 \\
\hline \multicolumn{7}{|l|}{ Affiliates } \\
\hline Contractibility & 46,627 & .03 & 0 & .12 & 0 & 1 \\
\hline Rule of Law & 73,563 & .73 & .81 & .16 & .13 & .89 \\
\hline Entry Cost & 73,064 & 1.6 & 2.15 & 1.57 & -6.91 & 7.63 \\
\hline
\end{tabular}

Table C3: Correlation matrix on control variables

\begin{tabular}{|c|c|c|c|c|c|c|c|c|c|}
\hline & $\begin{array}{l}\text { (log of) labor } \\
\text { productivity } j\end{array}$ & $\begin{array}{l}\text { (log of) } \\
\text { capital } \\
\text { intensity } j \\
\end{array}$ & $\begin{array}{l}\text { (log of) } \\
\text { employm } \\
\text { ent } j \\
\end{array}$ & $\begin{array}{l}\text { (log of) } \\
\text { number of } \\
\text { affiliates } j\end{array}$ & $\begin{array}{l}\text { (log of) } \\
\text { age } j\end{array}$ & $\begin{array}{l}\text { multinati } \\
\text { onal } \\
\text { group } j \\
\end{array}$ & $\begin{array}{l}\text { contracti } \\
\text { bility } i\end{array}$ & $\begin{array}{l}\text { rule of } \\
\text { law } i\end{array}$ & $\begin{array}{l}\text { entry } \\
\text { cost } i\end{array}$ \\
\hline $\begin{array}{l}\text { (log of) labor } \\
\text { productivity } j \\
\text { (log of) capital }\end{array}$ & 1.000 & & & & & & & & \\
\hline intensity $\boldsymbol{j}$ & 0.702 & 1.000 & & & & & & & \\
\hline $\begin{array}{l}\text { (log of) employment } j \\
\text { (log of) number of } \\
\text { affiliates } j\end{array}$ & $\begin{array}{r}-0.012 \\
0.186\end{array}$ & $\begin{array}{l}0.086 \\
0.289\end{array}$ & $\begin{array}{l}1.000 \\
0.717\end{array}$ & 1.000 & & & & & \\
\hline (log of) age $e_{j}$ & 0.053 & 0.015 & 0.280 & 0.241 & 1.000 & & & & \\
\hline multinational group $j$ & 0.150 & 0.169 & 0.346 & 0.368 & 0.152 & 1.000 & & & \\
\hline contractibility $i$ & 0.045 & 0.089 & -0.029 & -0.001 & 0.004 & -0.020 & 1.000 & & \\
\hline rule of law $c$ & 0.094 & 0.031 & -0.118 & -0.053 & -0.005 & 0.064 & -0.047 & 1.000 & \\
\hline entry cost $c$ & -0.025 & 0.013 & 0.115 & 0.070 & 0.045 & 0.011 & 0.003 & -0.590 & 1.000 \\
\hline
\end{tabular}


Table C4: Variants on sample composition for midstream parents

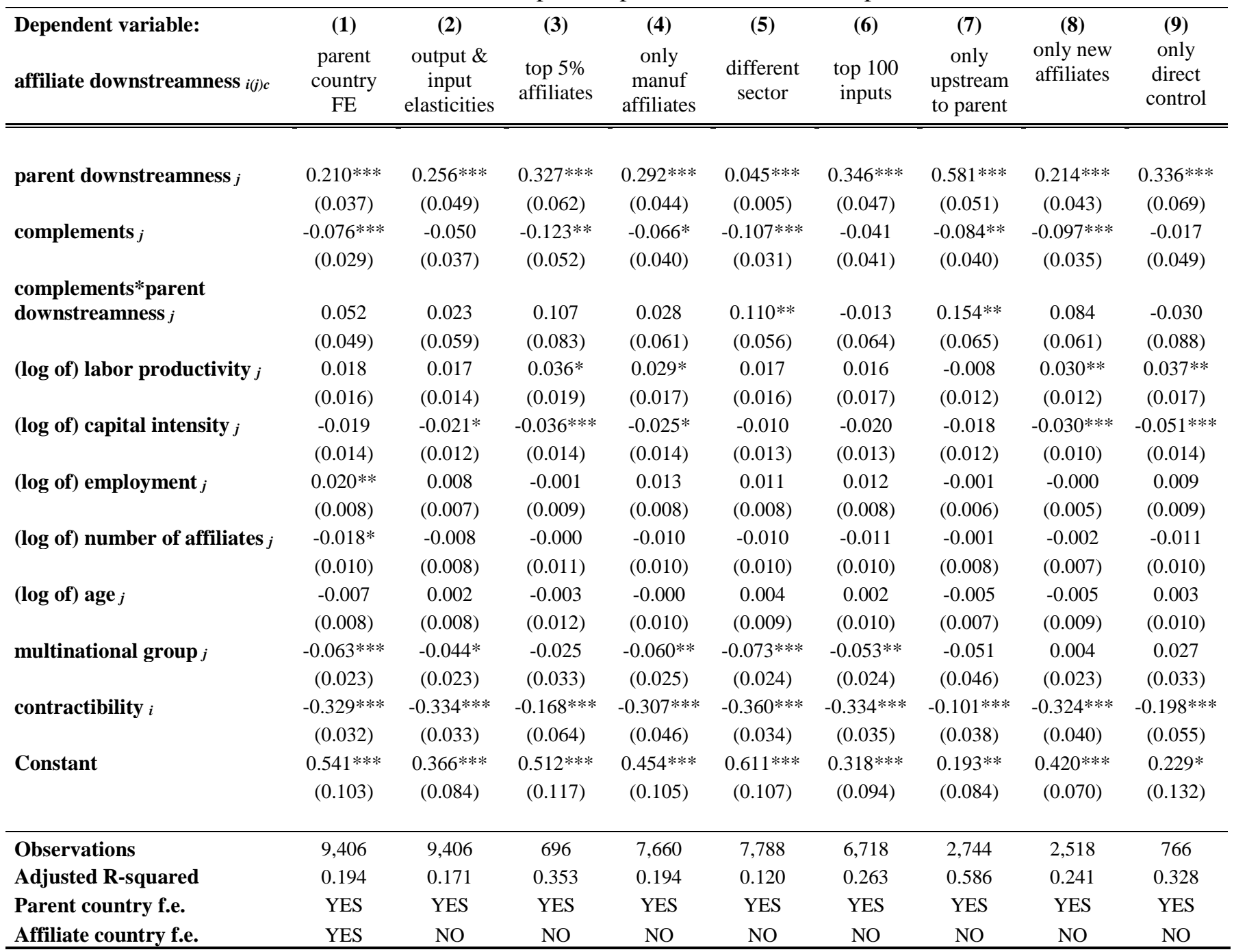

Errors clustered by parent in parentheses. ${ }^{* * *}, * *, *$ stand for $\mathrm{p}$-value $<0.01$, p-value $<0.05$ and p-value $<0.10$, respectively. 
Table C5: Fixed effects conditional logit _ inclusion of secondary activities

Dependent variable:

(1)

(2)

(3)

(4)

(5)

(6)

Input $m$ integrated by parent $j$ (Yes/No)

\begin{tabular}{|c|c|c|c|c|c|c|}
\hline relative downstreamness $m j$ & $\begin{array}{c}.446 * * * \\
(.013)\end{array}$ & $\begin{array}{c}.453^{* * *} \\
(.018)\end{array}$ & $\begin{array}{c}.393 * * * \\
(.023)\end{array}$ & $\begin{array}{c}.456 * * * \\
(.018)\end{array}$ & $\begin{array}{c}.429 * * * \\
(.028)\end{array}$ & $\begin{array}{c}.443 * * * \\
(.029)\end{array}$ \\
\hline complements* relative downstreamness $m j$ & $\begin{array}{c}.114^{* * *} \\
(.019)\end{array}$ & $\begin{array}{c}.137 * * * \\
(.026)\end{array}$ & $\begin{array}{c}.154 * * * \\
(.033)\end{array}$ & $\begin{array}{l}.056 * * \\
(.026)\end{array}$ & $\begin{array}{c}.132 * * * \\
(.039)\end{array}$ & $\begin{array}{c}.037 \\
(.042)\end{array}$ \\
\hline contractibility up-to-input $m j$ & & & & $\begin{array}{c}.012^{* * *} \\
(.003)\end{array}$ & $\begin{array}{c}.016 * * * \\
(.004)\end{array}$ & $\begin{array}{c}.005 \\
(.004)\end{array}$ \\
\hline contractibility up-to-input*complements $m j$ & & & & $\begin{array}{l}.008 * * \\
(.003)\end{array}$ & $\begin{array}{c}.000 \\
(.005)\end{array}$ & $\begin{array}{c}.021^{* * *} \\
(.006)\end{array}$ \\
\hline Dummy: Self-NAICS $m j$ & $\begin{array}{c}.612 * * * \\
(.012)\end{array}$ & $\begin{array}{c}.575 * * * \\
(.016)\end{array}$ & $\begin{array}{c}.671 * * * \\
(.019)\end{array}$ & $\begin{array}{c}.666^{* * *} \\
(.014)\end{array}$ & $\begin{array}{c}.646 * * * \\
(.020)\end{array}$ & $\begin{array}{c}.703 * * * \\
(.021)\end{array}$ \\
\hline Observations (parent per stage) & 280,660 & 131,436 & 113,035 & 262,698 & 123,676 & 105,546 \\
\hline Pseudo R-squared (McFadden's) & .144 & .143 & .144 & .151 & .147 & .155 \\
\hline Parent-level f.e. & YES & YES & YES & YES & YES & YES \\
\hline BEC category of parent & All & Intermediates & Final goods & All & Intermediates & Final goods \\
\hline
\end{tabular}

Robust standard errors in parentheses. ***, **, * stand for p-value $<0.01$, p-value $<0.05$ and $\mathrm{p}$-value $<0.10$, respectively. 


\section{MTT $\begin{aligned} & \text { SCHOOL } \\ & \text { FOR ADVANCED }\end{aligned}$ STUDIES LUCCA}

2017 @ IMT School for Advanced Studies, Lucca

Piazza San ponziano 6, 55100 Lucca, Italy. www.imtlucca.it 